Research Article

\title{
Evolutionary Game and Numerical Simulation of Cultivated Land Protection Policies Implementation in China
}

\author{
Xinhai Lu $\mathbb{D}^{1,}{ }^{1,2}$ Yanwei Zhang $\mathbb{D}^{1},{ }^{1}$ and Yucheng Zou $\mathbb{D}^{3}$ \\ ${ }^{1}$ College of Public Administration, Huazhong University of Science and Technology, Wuhan 430074, China \\ ${ }^{2}$ College of Public Administration, Central China Normal University, Wuhan 430079, China \\ ${ }^{3}$ School of Business, Central South University, Changsha 410083, China \\ Correspondence should be addressed to Yanwei Zhang; bsonyan@126.com
}

Received 22 July 2021; Revised 19 October 2021; Accepted 12 November 2021; Published 26 November 2021

Academic Editor: A. E. Matouk

Copyright (C) 2021 Xinhai Lu et al. This is an open access article distributed under the Creative Commons Attribution License, which permits unrestricted use, distribution, and reproduction in any medium, provided the original work is properly cited.

The effective implementation of cultivated land protection policies (CLPP) has important practical significance for improving China's food security and ecological security. The central government, local governments, and farmers have mutually restricted and influencing interest relations. At the same time, the codes of behavior of multistakeholders also affect the implementation of CLPP in the social system. Therefore, this article discusses the behavioral tendencies and game relationships of relevant stakeholders in the implementation of CLPP from the perspective of evolutionary games and portrays a cognitive decision-making process closer to reality. Finally, numerical simulation reveals the key variables that affect the stability strategy. Results show the following: (1) As the main body of system supply, the central government should reconstruct the political achievement evaluation system and improve the status of the effective implementation of cultivated protection policies in the political achievement evaluation of local governments. (2) The central government should increase incentives for local governments to implement CLPP and increase penalties for violations to improve the effectiveness of policy implementation. (3) To optimize the actual implementation of CLPP, increasing awareness of farmers' rights protection, reducing rights protection costs of farmers, and increasing the constraints on the flexible implementation of CLPP are necessary.

\section{Introduction}

Food is a special commodity and an important strategic reserve resource related to global human livelihoods. Food security is an integral part of the economic and social security and national security of all countries in the world [1]. As a developing country with a population of 1.4 billion, China's food security has an important impact on world food security [2]. Many factors influence food production, such as system and policy innovation [3], agricultural science and technology progress [4], and changes in cultivated land and environmental resources [5]. During the Thirteenth Five-Year Period, China's grain output has remained above 1.3 trillion catties for six consecutive years. The per capita grain has exceeded 470 kilograms, far above the international food security standard of 400 kilograms per capita. Such output has laid a solid material foundation for high-quality social and economic development in China and has contributed to China's efforts to stabilize international food prices, world agricultural development, and world food security.

Cultivated land is the basis for human survival and development. The quantity, quality, and ecological changes of cultivated land play an essential role in ensuring food security, ecological security, and regional sustainable development [6]. However, while China's cultivated land utilization and production has achieved the above-mentioned gratifying achievements, the increasing waste of cultivated land resources, soil pollution, and the destruction of the cultivated land ecosystem have restricted the sustainability of food production [7]. Since the reform and opening up, China's cultivated land protection work has been unremitting. At present, China's cultivated land protection policies (CLPP) arrangements mainly include land use planning, the dynamic equilibrium of the total cultivated land, land use control, crop rotation and fallow of cultivated 
land, land development, and reclamation and other related policies [8].

Land use planning system refers to the spatial and temporal strategic layout and overall planning of residential land use layout, land use zoning, basic farmland protection zone delineation, and cultivated land internal planning and design according to national socioeconomic development requirements and local natural, economic, and social conditions in a certain period and certain area. On this basis, the government conducts comprehensive land use balance accounting and planning implementation forecasts and proposes measures to ensure the implementation of the plan. The ultimate goal is to improve the degree of land intensive use and land use efficiency in the region and increase the agricultural output and income of farmers [9]. The dynamic balance of the total cultivated land means that the reduced and increased cultivated land in a certain period and within a certain administrative area maintain a dynamic balance in the total amount, and the quality of the cultivated land is the same [10]. Land use control indicates that to achieve the optimal allocation and rational use of land resources and promote the coordinated development of the social economy and land resources, the Chinese government permits, restricts, or disallows land use in accordance with land use and urban planning. On this basis, supervision, inspection, and follow-up management are implemented [11]. Cultivated land rotation and fallow system refers to measures implemented by landowners to protect, nurture, and restore soil fertility in a certain period to improve the efficiency of farming and realize the sustainable and effective use of cultivated land [12]. Cultivated land reclamation refers to the activities of implementing remediation measures to restore the cultivated land damaged by excavation, collapse, occupation, and other reasons in the production and construction to restore it to a reproducible state [13].

China has formed a complete and strict cultivated land protection system. However, problems continue to emerge that the effect of cultivated land protection is not optimistic and the implementation of CLPP is biased. For example, local governments use cultivated land quantity protection instead of cultivated land quality protection or lobby higherlevel governments to achieve synergy between efficiency and legality mechanisms. Furthermore, the occupation of cultivated land for construction land has phenomena, such as occupying more and making up for less, occupying advantages and making up for the disadvantages, misappropriating compensation, and wasting cultivated land resources. The fallow policy has insufficient fallow awareness, low fallow subsidies, and inadequate reasonable resettlement of fallow farmers [12]. For CLPP to become a reality, it must rely on each executive stakeholder's strong policy implementation power. If the policy cannot be effectively implemented, then a complete and reasonable policy system will eventually remain legal and become a dead letter. Therefore, how to improve the effectiveness of the implementation of CLPP and promote the sustainable use of cultivated land has become an urgent task to achieve the goals of cultivated land protection.
The CLPP is regarded as a typical public policy. On the one hand, cultivated land management and control objectives of local governments are inconsistent with those of the central government. The central government focuses on food security and cultivated land protection, whereas local governments are more concerned with land demand for economic development [14]. Given the huge dividends generated by the reform of land marketization, local governments expanded their financial resources through the sale of commercial or residential land and also sold extensive industrial land at low prices to attract investment, resulting in a strong demand for construction land. In the case of information asymmetry, when this demand cannot be met through legal land use indicators, local governments will selectively implement CLPP and use it to obtain additional land space, resulting in breakthroughs in various binding indicators. On the other hand, the central government currently strengthens the supervision of local government actions through the land inspection system, cultivated land occupation tax, and cultivated land vertical management system. However, to maintain local financial revenues, local governments use various methods to evade the supervision and inspection of the central government, thereby preventing various supervision policies from becoming effective. As a relatively opposing stakeholder, farmers have considerable autonomy in the implementation of CLPP. First, the property right system determines the various rights and obligations of farmers to cultivated land assets, thereby affecting their expected income from cultivated land protection. When farmers have stable management and profit rights to cultivated land assets, they will consider long term and exert their best effort to improve cultivated land quality. By contrast, if farmers cannot determine the management and income rights of cultivated land assets, then they will implement extensive management and pursue short-term economic gains. Second, when farmers can correctly understand CLPP and perceive the economic, social, and environmental benefits brought by cultivated land protection, they will unconsciously form cultivated land protection awareness and adopt cultivated land protection behaviors in production practices [15].

Scholars have conducted extensive research on improving the implementation of CLPP, mainly focusing on the influence of factors, such as individual or family characteristics of farmers, livelihood capital, degree of concurrent employment, interest statement, consciousness differentiation, cognitive level, and satisfaction degree on the implementation of CLPP [16-18]. Some scholars have also researched institutional changes, regional differences, and nonmarket value $[19,20]$. However, some limitations emerged. CLPP of China is a strategic and overall public system concerning the national economy and people's livelihood in China. Furthermore, cultivated land has apparent characteristics, such as fixed location, perpetual utilization, and scarcity of resources [21]. The formation of its policy implementation power is a typical system engineering and requires the joint efforts of the whole society. The stakeholders of cultivated land protection are many, and the role of each stakeholder varies. The cultivated land's 
actual cultivator (farmers) is the protagonist in the protection of cultivated land. In contrast, the central government and the local government are the common stakeholders and need to be coordinated and coordinated at the macrolevel [22]. Therefore, the implementation of CLPP takes place on a complex network of relationships. Whether it can achieve the optimal allocation of cultivated land resources while balancing the relationship between various stakeholders to ensure the interests of farmers, social interests, and national interests is an important basis for improving the effectiveness of cultivated land protection. However, given stakeholders' different interests in the implementation of CLPP, the information asymmetry of each stakeholder, and the influence of irrational factors, the implementation effect of CLPP often depends on the game strategies of the stakeholders. This explanation is also the main reason for the failure to implement the CLPP in a highpressure environment where the cultivated land inspection mechanism is relatively sound, the CLPP is relatively strict, and the punishment for cultivated land violations is relatively increased [23].

Game analysis lies in establishing an appropriate restraint mechanism or incentive mechanism by analyzing the different strategic choices of stakeholders to achieve the expected stable equilibrium state [24, 25]. Compared with the traditional game theory, the evolutionary game theory relaxes the assumptions and belongs to the benefit analysis under bounded rationality $[26,27]$. In the study of strategy adjustments, trends, and local stability issues in repeated long-term games, the evolutionary game analysis with bounded rationality can better reflect the dynamic decisionmaking relationships and decision-making behaviors of multiple stakeholders. At present, evolutionary game theory has been widely used in the selection mechanism of cultivated land protection behavior [28-30]. However, the theoretical results of some scholars only focus on the analysis of common factors, such as supervision costs and benefits, supervision intensity, implementation costs and benefits, and rewards and punishments and whether they impact the game results of the implementation of CLPP. It has not thoroughly analyzed how various factors affect the behavioral strategies of stakeholders in the game and has ignored the impact of nonagricultural benefits, political performance, and trust risk on the results of the game.

Why did the CLPP formulated by the central government fail to achieve the expected effects? From the source governance perspective, local governments have vigorously promoted land finance after the reform of the tax-sharing system to complete fiscal expenditure. In this mode, local governments will inevitably have illegal operations. Given that the land inspection system has yet to be completed, whether the phenomenon of flexible implementation of CLPP can be investigated and punished depends on the central government's intensity of supervision. However, the intensity of punishment has a threshold effect on the result of system evolution. The current research attempts to explore the punishment threshold and establish the critical line of punishment through theoretical and simulation analyses. This undertaking helps local governments have sufficient motivation and conditions to faithfully implement the CLPP formulated by the central government. Under the combined effects of power and capital, policy benefits will be blocked by the strong class, and the weak class (e.g., farmers) can only enjoy a small part of the benefits. When the rights and interests of disadvantaged group members are seriously affected, they will use their own disadvantaged position and government pressure to maintain social stability to strategically defend their rights, causing disadvantaged groups to resist. However, the strength of local governments, weakness of farmers, and high cost of safeguarding rights are key factors that make the game result deviate from the optimal social equilibrium. Therefore, this study explores the evolutionary equilibrium state of local governments and farmers under different rights' protection costs to enhance the enthusiasm of farmers to protect cultivated land.

Thus, to examine the deficiencies and problems in the implementation of CLPP, this study introduces evolutionary game theory method to construct an evolutionary game model for the implementation of CLPP. Through numerical simulation, an in-depth study is conducted on how various factors affect the dynamic strategy selection and control strategy of various stakeholders about policy implementation in different situations to provide theoretical support to realize the ideal situation of cultivated land protection.

\section{Evolutionary Game Model of the Implementation of CLPP}

2.1. Model Hypothesis. The evolutionary game is based on the premise of bounded rationality, with the group as the research object, and analyzes the dynamic evolutionary process of the stakeholders. It also explains why and how the group reaches the current state, emphasizes the influence of the process of behavior evolution on the outcome of equilibrium, and believes that equilibrium is a function of the process of reaching equilibrium $[31,32]$. The implementation of CLPP by the central government, local governments, and farmers is uncertain and bounded rationally. It is a dynamic evolutionary process of learning changes over time. According to the relevant theories of stakeholders and evolutionary game models, the assumptions of this article are explained as follows:

(i) Hypothesis 1. System theory: In the natural environment that does not consider other constraints, the composition of the central government, local governments, and farmers is regarded as a complete system. The three stakeholders in the system are all individuals with learning ability and bounded rationality and have their own behavioral choices and powers.

(ii) Hypothesis 2. Two-to-two game: Although the central government, local governments, and farmers face all the individuals of another group when implementing CLPP, the game is assumed to be played between two stakeholders.

(iii) Hypothesis 3. Myopia: Suppose that when a stakeholder changes his strategy, he always takes the 
current strategy distribution as the known condition and then changes to another strategy corresponding to this. This stakeholder does not consider the changes in the strategy space and payment function caused by the other stakeholders changing their strategies [33].

\subsection{Model Construction}

2.2.1. Construction of the Game Model between the Central Government and Local Government. The central government represents national interests, is the macromanager of cultivated land and the policymaker of cultivated land protection, and ensures that the amount of cultivated land and the area of basic farmland are not reduced. The current central government implements an active CLPP and is a target management system under a compulsory administrative system. However, the central government and local governments have formed an apparent relationship of commission and agency. Local governments act on behalf of the central government to implement CLPP, carry out macromanagement and regulation of regional cultivated land resources, and complete specific tasks assigned by the central government. At the same time, local governments also act as an agent for nongovernmental stakeholders (farmers, rural collective economic organizations, and rural enterprises) in the region to promote economic development to maximize regional economic benefits. Under the multitask agency, the reward and punishment mechanism of the central government and the monitoring intensity of policy objectives directly affects the behavior of the local government. Given local governments' strong political and economic demands, they are more concerned with developing the local economy, achieving rapid growth in fiscal revenue, and maximizing political performance during the term of office. However, local governments dare not directly violate the CLPP of the central government. They can only adopt selective implementation, coping actions, and flexible execution methods because of the superior-subordinate relationship between local governments and the central government.

Compared with other studies, the main contribution of this research is that it considers central government supervision costs, rewards or penalties for local governments, place differences in implementation costs caused by different implementation attitudes of local governments, improvement or decline of political achievements of local government, and increase or decrease in the total value of cultivated land simultaneously. Supervision behavior of the central government refers to its role solely as supervisor under the premise of the established CLPP. Hence, policy-making behavior is excluded in the analysis of this research. However, the attitude of local government toward the implementation of CLPP is based on its interest orientation; if it conforms to its own interest, then it will strive to implement it faithfully; and if it does not conform to its own interest, then it will be implemented flexibly. Therefore, different policy implementation attitudes significantly affect the input level of implementation costs. In addition, the central government will give economic rewards, honorary incentives, or promotion of officials to local governments that have made outstanding contributions to the CLPP implementation; otherwise, they will be punished. This situation can promote the local government to devote considerable enthusiasm to the work of cultivated land protection. The total value of cultivated land includes economic, social, and ecological values. On this basis, the preceding factors are incorporated into the same framework for decision-making analysis. Moreover, the optimal decision-making behavior of the central government and local governments on CLPP implementation is constructed, thereby illustrating the existence of equilibrium point. Given the inconsistency of behavioral starting points, the following game strategies exist between the central government and local government (see Table 1).

(1) Stakeholders. Central government $(G)$ and local government (LG).

(2) Strategic Space. The strategic space of the central government is $S_{G}=\{$ Strict supervision, Slack supervision\}, the probability of strict supervision by the central government is $p$, and the probability of slack supervision is $1-p$. The strategic space of the local government is $S_{\mathrm{LG}}=\{$ Faithful implementation, Flexible implementation $\}$, the probability of faithful implementation by the local government is $q$, and the probability of flexible execution is $1-q$.

(3) Payoff Function.

(1) When the central government conducts strict supervision and the local government conducts faithful implementation, the payment cost by the central government is the direct cost of strict supervision $\left(C_{1}\right)$ and the economic reward to the local government $\left(C_{2}\right)$. The revenue of the central government is the total value of cultivated land acquired by the central government $\left(D_{1}\right)$. The total value of cultivated land can be defined as economic output value, social value (including social security value and food security value), and ecological value. The payment cost by the local government is the direct cost of the local government's faithful implementation of CLPP $\left(B_{1}\right)$. The revenue of the local government includes the total value of the cultivated land obtained by the local government $\left(E_{1}\right)$ and the award from the central government to the local government $\left(A_{1}\right)$. It consists of the improvement of political performance brought about by the cultivated land protection $\left(G_{1}\right)$ and the economic rewards by the central government $\left(C_{2}\right)$.

(2) When the central government conducts strict supervision and the local government conducts flexible implementation, the payment cost by the central government is $\left(C_{1}+D_{1}\right)$, and the revenue is the economic penalties imposed by the central government on local government $\left(W_{1}\right)$. The payment cost 
TABLE 1: Payoff matrix of the central government and the local government.

\begin{tabular}{|c|c|c|c|}
\hline \multirow{2}{*}{\multicolumn{2}{|c|}{ Stakeholders and their strategies }} & \multicolumn{2}{|c|}{ Local government } \\
\hline & & Faithful implementation $(q)$ & Flexible implementation $(1-q)$ \\
\hline Central government & $\begin{array}{l}\text { Strict supervision }(p) \\
\text { Slack supervision }(1-p)\end{array}$ & $\begin{array}{c}D_{1}-C_{1}-C_{2} \\
E_{1}+A_{1}-B_{1} \\
D_{1}-P_{1} \\
E_{1}-B_{1} \\
\end{array}$ & $\begin{array}{c}W_{1}-C_{1}-D_{1} \\
J_{1}-B_{3}-A_{2}-E_{1} \\
-D_{1}-P_{1} \\
J_{1}+O_{1}-B_{3}-E_{1}\end{array}$ \\
\hline
\end{tabular}

by the local government includes the cost of flexible implementation of the CLPP $\left(B_{3}\right)$, the penalty of the central government to the local government $\left(A_{2}=\right.$ political penalty $\left(G_{2}\right)$ +economic penalty $\left.\left(W_{1}\right)\right)$, and the loss of the total value of the cultivated land $\left(E_{1}\right)$. The revenue of the local government is the income formed by the cultivated land conversion $\left(J_{1}\right)$.

(3) When the central government conducts slack supervision and the local government conducts faithful implementation, the payment cost by the central government is the direct cost of slack supervision $\left(P_{1}, P_{1}<C_{1}\right)$, and the revenue is $D_{1}$. The payment cost by the local government is $B_{1}$, and the revenue is $E_{1}$.

(4) When the central government conducts slack supervision and the local government conducts flexible implementation, the payment cost by the central government is $P_{1}+D_{1}$, and the revenue is 0 . The payment cost by the local government is $B_{3}+E_{1}$, and the revenue includes the improvement of the level of political performance brought about by economic development $\left(O_{1}\right)$ and $J_{1}$.

2.2.2. Construction of the Game Model between the Local Government and Farmers. Local governments must abide by the CLPP of central government and seek to maximize their benefits. Farmers in traditional agriculture are rational economic men, and their economic behavior conforms to the assumptions of rational economic men in economics. They take self-interest as the starting point; comprehensively consider costs, benefits, and various risks; and strive to achieve the greatest economic benefits with the least cost. As a means of production on which farmers depend for survival, cultivated land has functions of income, social security, and employment. Farmers can obtain corresponding benefit compensation in the process of nonagriculturalization of cultivated land, and nonagricultural income can increase. However, nonagriculturalization breaks farmers' dependence on the familiar environment, which can easily lose the original tightly connected CLAN network and increase survival costs.

Furthermore, an irrational land property rights system in China can easily cause farmers to be in an unfair and unreasonable position to distribute cultivated land increment income. The opaque procedures, the use of force on cultivated land conversion, and the inadequacy of compensation payments make it easy for farmers to feel resistance and breed conflicts. When farmers feel that their rights and interests have been damaged, they may choose to apply for an audience with higher authorities to appeal for help, legal proceedings, and excessive actions to safeguarding rights. Rights-safeguarding activities require farmers to pay time and money costs and sometimes lead to conflicts and loss of life and health. At the same time, given the neglect of the externalities of cultivated land protection behavior of farmers, no socialized compensation mechanism for cultivated land protection of farmers is found. Therefore, if farmers cannot obtain reasonable compensation for the external benefits, such as environmental ecology and food security, farmers will gradually lose their enthusiasm for implementing CLPP. Furthermore, suppose the income effect of a nonagricultural part-time job is noticeable. In that case, farmers will prefer nonagricultural industries in the decision-making of cultivated land resource allocation and only use cultivated land as a livelihood guarantee. Their dependence on cultivated land will be relatively weakened.

Compared with other research, the main contribution of this study is that reputation level of the local government, agricultural income level of farmers, social security function of cultivated land, training costs for farmers engaged in nonagricultural economic activities, compensation received by farmers after nonagriculturalization of cultivated land, and rights' protection costs of farmers are considered simultaneously. The inaction of local governments in the protection of cultivated land may be exposed by farmers, thereby possibly having a negative impact on their reputation. The management scale, quality level, and food supply function of cultivated land determine the efficiency of agricultural production and level of agricultural income of farmers. Cultivated land, as a family asset, plays a role in guaranteeing the employment and pension of farmers. By relying on cultivated land, farmers can maintain and meet basic household consumption. The strength of the social security function of cultivated land depends on its total value. Participation of farmers in nonagricultural training is conducive to their mastery of nonagricultural technology and knowledge. However, nonagricultural training costs are a relatively large expense for some poor farmers. Nonagriculturalization will inevitably result in the loss of the multifunctional service value of cultivated land. In addition, reasonable compensation should be provided for the multifunctional value of cultivated land lost by the corresponding entities to strengthen the protection of farmers' livelihoods. Rights protection costs of farmers include economic, program, and time costs. Accordingly, the innovation of this research is to fully consider various influencing factors when constructing the game model. On the basis of the results of game analysis, this research proposes feasible policy implications from the perspective of rights 
protection costs of farmers. Given the inconsistency of comparative interests, the following game strategies exist between local governments and farmers (see Table 2).

(1) Stakeholders. Local government (LG) and farmer $(F)$.

(2) Strategic Space. The strategic space of the local government is $S_{\mathrm{LG}}=\{$ Faithful implementation, Flexible implementation $\}$, the probability of faithful implementation by the local government is $q$, and the probability of flexible execution is $1-q$. The strategic space of farmers is $F=\{$ Cooperation, Resistance $\}$, the probability of cooperation by farmers is $\partial$, and the probability of resistance is $1-\partial$.

(3) Payoff Function.

(1) When the local government conducts faithful implementation and farmers cooperate, the payment cost by the local government is $B_{1}$, the revenue is $E_{1}$, and the increase of farmers' trust in local governments is $H_{3}$. The payment cost by farmers is 0 , and the revenue is the total value of the cultivated land obtained by farmers $\left(I_{3}\right)$.

(2) When the local government conducts faithful implementation and farmers resist, the payment cost by the local government is $B_{1}+E_{1}$, and the revenue is 0 . The payment cost by farmers includes the decline in agricultural income caused by the nonagriculturalization of cultivated land $\left(Z_{1}\right)$ and loss of relevant subsistence guarantees for farmers dependent on cultivated land $\left(Z_{2}\right)$. The training costs need to be paid to find another job after losing cultivated land to maintain the livelihood $\left(Z_{3}\right)$ and $I_{3}$. Let $Z_{1}+Z_{2}+Z_{3}=L_{1}$. The revenue of farmers is the rise of nonagricultural income $M_{1}$.

(3) When local government conducts flexible implementation and farmers cooperate, the payment cost by the local government includes $B_{3}+E_{1}$, compensation to farmers by the local government, including economic compensation, recovery in-kind and other related social security compensation $\left(H_{1}\right)$, and the political risk caused by the loss of farmers' trust in the government $\left(H_{3}\right)$. Let $N_{1}=H_{1}+H_{3}$. The revenue of the local government is $J_{1}$. The payment cost by farmers is $L_{1}+I_{3}$, and the revenue is $M_{1}+H_{1}$.

(4) When local government conducts flexible implementation and farmers resist, the payment cost by the local government is $H_{3}+B_{3}$, and the revenue is $E_{1}$. The payment cost by farmers is $H_{1}, H_{5}$ represents the expenses that farmers need to pay to protect the cultivated land, and the revenue is $I_{3}$.

2.3. Stability Analysis of the Implementation of CLPP. The action strategies among the central government, the local government, and farmers interact with and adjust to one another. Each stakeholder will inevitably make continuous adjustments to strategic choices to maximize the expected revenue. Therefore, in the process of constructing the CLPP system and policy implementation, comprehensively considering the main factors that affect the payment function and controlling the changes of these factors are necessary to guide the stakeholders to choose a strategy that is conducive to the implementation of the CLPP. In this section, the replicator dynamics equation is used to solve and reveal the formation conditions and processes of different evolutionary stability strategies of various stakeholders.

2.3.1. Evolutionary Stable Strategies of the Central Government and Local Governments. Given $q$, suppose $U_{G 1}$ is the expected revenue when the central government adopts strict supervision, $U_{G 2}$ is the expected revenue when the central government adopts slack supervision, $U_{\mathrm{LG} 1}$ is the expected revenue when the local government adopts faithful implementation, and $U_{\mathrm{LG} 2}$ is the expected revenue when the local government adopts slack implementation. The expected revenue of the central government and the local government is as follows:

$$
\begin{aligned}
U_{G 1} & =q\left(D_{1}-C_{1}-C_{2}\right)+(1-q)\left(W_{1}-C_{1}-D_{1}\right), \\
U_{G 2} & =q\left(D_{1}-P_{1}\right)+(1-q)\left(-D_{1}-P_{1}\right), \\
U_{L G 1} & =p\left(E_{1}+A_{1}-B_{1}\right)+(1-p)\left(E_{1}-B_{1}\right), \\
U_{L G 2} & =p\left(J_{1}-B_{3}-A_{2}-E_{1}\right)+(1-p)\left(J_{1}+O_{1}-B_{3}-E_{1}\right) .
\end{aligned}
$$

The level payments of the central government and local government when making strategic choices are as follows:

$$
\begin{aligned}
\overline{U_{G}} & =p U_{G 1}+(1-p) U_{G 2}, \\
\overline{U_{L G}} & =q U_{L G 1}+(1-q) U_{L G 2} .
\end{aligned}
$$

From evolutionary game theory, the replicator dynamics equation between the central government and the local government can be obtained as follows:

$$
\begin{aligned}
& F(p)=\frac{\mathrm{d} p}{\mathrm{~d} t}=p(1-p)\left[q\left(P_{1}-C_{1}-C_{2}\right)+(1-q)\left(W_{1}-C_{1}+P_{1}\right)\right] \\
& \left.F(q)=\frac{\mathrm{d} q}{\mathrm{~d} t}=q(1-q)\left[p\left(2 E_{1}+A_{1}-B_{1}-J_{1}+B_{3}+A_{2}\right)\right]+(1-p)\left(2 E_{1}-B_{1}-J_{1}+O_{1}+B_{3}\right)\right] .
\end{aligned}
$$


TABLE 2: Payoff matrix of the local government and farmers.

\begin{tabular}{|c|c|c|c|}
\hline \multirow{2}{*}{\multicolumn{2}{|c|}{ Stakeholders and their strategies }} & \multicolumn{2}{|c|}{ Farmer } \\
\hline & Hitil stialcgits & Cooperation $(\partial)$ & Resistance $(1-\partial)$ \\
\hline Local government & $\begin{array}{c}\text { Faithful implementation }(q) \\
\text { Flexible implementation }(1-q)\end{array}$ & $\begin{array}{c}E_{1}+H_{3}-B_{1} \\
\quad I_{3} \\
J_{1}-N_{1}-B_{3}-E_{1} \\
M_{1}+H_{1}-L_{1}-I_{3}\end{array}$ & $\begin{array}{c}-E_{1}-B_{1} \\
M_{1}-L_{1}-I_{3} \\
E_{1}-H_{3}-B_{3} \\
I_{3}-H_{1}-H_{5} \\
\end{array}$ \\
\hline
\end{tabular}

According to the two-dimensional differential theorem, the possible equilibrium points of this system are $(0,0)$, $(0,1),(1,0),(1,1)$, and $\left(p^{*}, q^{*}\right)$.

$$
\begin{aligned}
& \text { Let } F(p)=0, \text { get } q^{*}=\frac{W_{1}-C_{1}+P_{1}}{C_{2}+W_{1}}, \\
& \text { Let } F(q)=0, \text { get } p^{*}=\frac{O_{1}-A_{1}-A_{2}}{2 E_{1}-B_{1}-J_{1}+O_{1}+B_{3}} .
\end{aligned}
$$

According to evolutionary equilibrium theory, judging the asymptotic stability of the replicator dynamic equilibrium point needs to be tested using the local stability analysis method of the Jacobian matrix. The Jacobian matrix is as follows:

$$
J=\left[\begin{array}{ll}
\frac{\partial F(p)}{\partial p} & \frac{\partial F(p)}{\partial q} \\
\frac{\partial F(q)}{\partial p} & \frac{\partial F(q)}{\partial q}
\end{array}\right]=\left[\begin{array}{ll}
a_{11} & a_{12} \\
a_{13} & a_{14}
\end{array}\right]
$$

$a_{11}, a_{12}, a_{13}$, and $a_{14}$ are as follows:

$$
\begin{aligned}
& a_{11}=\frac{\partial F(p)}{\partial p}=(1-2 p)\left[\left(W_{1}-C_{1}+P_{1}\right)+q\left(-C_{2}-W_{1}\right)\right], \\
& a_{12}=\frac{\partial F(p)}{\partial q}=p(1-p)\left(-C_{2}-W_{1}\right), \\
& a_{13}=\frac{\partial F(q)}{\partial p}=q(1-q)\left(A_{1}+A_{2}-O_{1}\right), \\
& a_{14}=\frac{\partial F(q)}{\partial q}=(1-2 q)\left[\left(2 E_{1}-B_{1}-J_{1}+O_{1}+B_{3}\right)+p\left(A_{1}+A_{2}-O_{1}\right)\right] .
\end{aligned}
$$

Only when the determinant and trace of $J$ satisfy Det $J=a_{11} a_{14}-a_{12} a_{13}>0, \operatorname{Tr} J=a_{11}+a_{14}<0$, the system equilibrium point of the evolutionary game between the central government and the local government can be judged (see Table 3).

When analyzing the matrix eigenvalues, symbols, determinant, and trace of the above five possible equilibrium points in Table 3, this study finds that the strategic stability of the central government and local governments are affected by specific parameters.

When $Z<0, S<0, Y<0$, and $K>0$, two equilibrium points can be obtained, which are $A(0,0)$ and $D(1,1)$, respectively (see Figure 1). When the central government conducts slack supervision, the benefits of flexible implementation by the local government are greater than those of faithful implementation. When the central government conducts strict supervision, the benefits of faithful implementation by the local government are greater than those of flexible implementation. When the local government conducts flexible implementation, the benefits of slack supervision are greater than those of strict supervision. The reason is as follows: (1) When the penalties obtained by the central government are not enough to offset the supervision costs, the central government tends to choose the strategy of slack supervision. Furthermore, when the local government faithfully implements CLPP, if the cost is high and the total value of the cultivated land obtained is far less than the nonagricultural benefits, it tends to achieve the goal of CLPP through various informal means. (2) The central government and local government are not short-sighted stakeholders who only consider the costs and benefits of CLPP implementation. As a representative of public interest, the local government considers the gains and losses of the political performance caused by the faithful implementation and flexible implementation of CLPP. Simultaneously, the central government makes arrangements for rewards and punishments based on the implementation of CLPP by the local government. Therefore, improving the status of the implementation of CLPP in the political performance evaluation of the local government can mobilize the inherent incentives for its faithful implementation.

2.3.2. Evolutionary Stable Strategies of the Local Government and Farmers. Given $q, U_{\mathrm{LG} 1}$ is the expected revenue when the local government adopts faithful implementation, and 
TABLE 3: Analysis of the stability of the equilibrium point between the central government and the local government.

\begin{tabular}{|c|c|c|c|c|}
\hline Equilibrium point & $a_{11}$ & $a_{12}$ & $a_{13}$ & $a_{14}$ \\
\hline $\begin{array}{l}A(0,0) \\
B(0,1) \\
C(1,0) \\
D(1,1) \\
E\left(p^{*}, q^{*}\right)\end{array}$ & $\begin{array}{c}W_{1}-C_{1}+P_{1} \\
P_{1}-C_{1}-C_{2} \\
-\left(W_{1}-C_{1}+P_{1}\right) \\
-\left(P_{1}-C_{1}-C_{2}\right) \\
0\end{array}$ & $\begin{array}{l}0 \\
0 \\
0 \\
0 \\
P\end{array}$ & $\begin{array}{l}0 \\
0 \\
0 \\
0 \\
Q\end{array}$ & $\begin{array}{c}2 E_{1}-B_{1}-J_{1}+O_{1}+B_{3} \\
-\left(2 E_{1}-B_{1}-J_{1}+O_{1}+B_{3}\right) \\
2 E_{1}-B_{1}-J_{1}+B_{3}+A_{1}+A_{2} \\
-\left(2 E_{1}-B_{1}-J_{1}+B_{3}+A_{1}+A_{2}\right) \\
0\end{array}$ \\
\hline Numerical & Symbols & Numerical & Symbols & Stability \\
\hline $\begin{array}{l}Z * S \\
Y *(-S) \\
(-Z) * K \\
(-Y) *(-K) \\
P * Q\end{array}$ & $\begin{array}{l}+ \\
- \\
- \\
+\end{array}$ & $\begin{array}{c}Z+S \\
Y-S \\
(-Z)+K \\
(-Y)-K \\
0\end{array}$ & $\begin{array}{l}- \\
- \\
+ \\
-\end{array}$ & $\begin{array}{c}\text { ESS } \\
\text { Unstable point } \\
\text { Unstable point } \\
\text { ESS } \\
\text { Saddle point }\end{array}$ \\
\hline
\end{tabular}

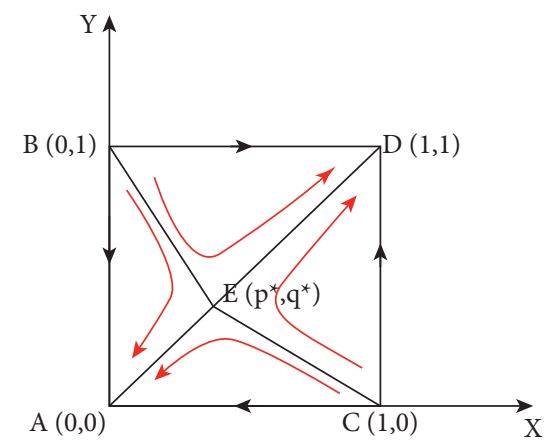

Figure 1: Copying dynamic phase diagram of the central government and the local government.

$U_{\mathrm{LG} 2}$ is the expected revenue when the local government adopts slack implementation. $U_{F 1}$ is the expected revenue when farmers adopt the cooperation strategy, $U_{F 2}$ is the expected revenue when farmers adopt the resistance strategy. The expected revenues of the local government and farmers are as follows:

$$
\begin{aligned}
U_{\mathrm{LG} 1} & =\partial\left(E_{1}+I_{3}\right)+(1-\partial)\left(-E_{1}-B_{1}\right), \\
U_{\mathrm{LG} 2} & =\partial\left(J_{1}-N_{1}-B_{3}-E_{1}\right)+(1-\partial)\left(E_{1}-H_{3}-B_{3}\right), \\
U_{F 1} & =q I_{3}+(1-q)\left(M_{1}+H_{1}-L_{1}-I_{3}\right), \\
U_{F 2} & =q\left(M_{1}-L_{1}-L_{3}\right)+(1-q)\left(I_{3}-H_{1}-H_{5}\right) .
\end{aligned}
$$

The level payments of the local government and farmers when making strategic choices are as follows:

$$
\begin{aligned}
\overline{U_{\mathrm{LG}}} & =q U_{\mathrm{LG} 1}+(1-q) U_{\mathrm{LG} 2}, \\
\overline{U_{F}} & =\partial U_{F 1}+(1-\partial) U_{F 2} .
\end{aligned}
$$

From evolutionary game theory, the replicator dynamics equation between the local government and farmers can be obtained as follows:

$$
\begin{aligned}
F(q)= & \frac{\mathrm{d} q}{\mathrm{~d} t}=q(1-q)\left[\partial\left(2 E_{1}+H_{3}-B_{1}-J_{1}+N_{1}+B_{3}\right)\right. \\
& \left.+(1-\partial)\left(-2 E_{1}-B_{1}+H_{3}+B_{3}\right)\right] \\
F(\partial)= & \frac{\mathrm{d} \partial}{\mathrm{d} t}=\partial(1-\partial)\left[q\left(2 I_{3}-M_{1}+L_{1}\right)+(1-q)\right. \\
& \left.\left(M_{1}+2 H_{1}-L_{1}-2 I_{3}+H_{5}\right)\right] .
\end{aligned}
$$

The possible equilibrium points of this system are $(0,0)$, $(0,1),(1,0),(1,1)$, and $\left(q^{*}, \partial^{*}\right)$.

$$
\begin{aligned}
& \operatorname{Let} F(q)=0, \text { get } \partial^{*}=\frac{2 E_{1}+B_{1}-H_{3}-B_{3}}{4 E_{1}-J_{1}+N_{1}}, \\
& \text { Let } F(\partial)=0, \text { get } q^{*}=\frac{L_{1}+2 I_{3}-M_{1}-2 H_{1}-H_{5}}{4 I_{3}-2 M_{1}+2 L_{1}-2 H_{1}-H_{5}} .
\end{aligned}
$$

The local stability analysis method of the Jacobian matrix is also used for testing this system. The Jacobian matrix is as follows: 


$$
J^{*}=\left[\begin{array}{ll}
\frac{\partial F(q)}{\partial q} & \frac{\partial F(q)}{\partial \partial} \\
\frac{\partial F(\partial)}{\partial q} & \frac{\partial F(\partial)}{\partial \partial}
\end{array}\right]=\left[\begin{array}{ll}
a_{21} & a_{22} \\
a_{23} & a_{24}
\end{array}\right] .
$$

Among them, $a_{21}, a_{22}, a_{23}$, and $a_{24}$ are as follows:

$$
\begin{aligned}
& a_{21}=(1-2 q)\left[-2 E_{1}-B_{1}+H_{3}+B_{3}+\partial\left(4 E_{1}-J_{1}+N_{1}\right)\right], \\
& a_{22}=q(1-q)\left(4 E_{1}-J_{1}+N_{1}\right), \\
& a_{23}=\partial(1-\partial)\left(4 I_{3}-2 M_{1}+2 L_{1}-2 H_{1}-H_{5}\right), \\
& a_{24}=(1-2 \partial)\left[M_{1}+2 H_{1}-L_{1}-2 I_{3}+H_{5}+q\left(4 I_{3}-2 M_{1}+2 L_{1}-2 H_{1}-H_{5}\right)\right] .
\end{aligned}
$$

The determinant and trace of $J^{*}$ are used to determine the system equilibrium point of the evolutionary game between the local government and farmers.

When analyzing the matrix eigenvalues, symbols, determinant, and trace of the above five possible equilibrium points in Table 4, we find that the strategic stability of the local governments and farmers is affected by specific parameters.

When $R<0, U>0, T<0$, and $X<0$, one equilibrium point can be obtained, which is $B^{*}(0,1)$ (see Figure 2). When the local government conducts flexible implementation strategies, the benefits of the cooperative behaviors of farmers outweigh the resistance behaviors. The reason is that, when local governments implement CLPP flexibly, farmers are more willing to convert cultivated land to nonagricultural land to obtain high compensation fees for land expropriation. Furthermore, the local government that enjoys the power of institutional design can occupy the initiative in the game limitedly, control the dynamic development of the entire game, and obtain the maximum benefit of the game. The local government uses illegal and concealed means to promote the conversion of cultivated land into urban construction land and can exercise grey control over farmers through rent-seeking behavior. In reality, the right-safeguarding methods of farmers are limited, and farmers choose to remain silent and cooperate when facing local government conduct the flexible implementation of CLPP because of poor petition channels, unreasonable delays in petitions, and poor petition effects.

\section{Numerical Simulation}

We can find through the stability analysis of the equilibrium point that, under the implementation framework of the CLPP, the equilibrium point $D(1,1)$ is the best ideal state to improve the level of implementation of the CLPP. Under the strict supervision of the central government, CLPP can be implemented by more local governments and farmers. The central government should exercise administrative control over the local government and ensure the paths for farmers to participate in cultivated land protection to achieve optimal control of the ideal evolutionary stable equilibrium state of "the central government puts pressure, local government implements, and farmer participates." This section simulates the evolutionary path of the system converging to an ideal stable equilibrium state by changing the value of each parameter and analyzes the influence of different parameters on the evolutionary stability strategy adopted by the game stakeholders to examine the nature and practicability of the model constructed in this article.

3.1. Impact of Punishment Intensity on the State of Evolutionary Equilibrium. According to the game payoff matrix, the punishment intensity A_2 significantly impacts local government behavior. Therefore, this article treats the remaining parameters as constants to facilitate the analysis of the proportional relationship between the punishment intensity and the implementation of CLPP. When the central government adopts the slack supervision strategy, the change in the value of $A_{2}$ has a greater impact on the game system. As the value of $A_{2}$ continues to increase, based on the consideration of costs and benefits, rational local government is more inclined to implement the game strategy of flexible implementation of CLPP with higher benefits. Thus, a higher level of political performance can be achieved in competitive appointments with the government at the same level. Initially, the central government and the local governments are assumed to have a probability of 0.5 to select different behavioral decisions. When $A_{2}$ takes values of 6,5 , 4 , and 3 , numerical simulation analysis is performed, and the evolution trajectory is shown in Figure 3. At this time, the stability point of the evolutionary game system of the central government and the local government is $A(0,0)$, and the stability strategies of the stakeholders of the game are slack supervision and flexible implementation. Under the penalty mechanism, the probability of local governments adopting flexible implementation fluctuates over time. First, under the constraints of a series of land management methods and punishment mechanisms, the contradictions and conflicts between cultivated land protection and construction land expansion can be effectively alleviated. Thus, the faithful implementation of the CLPP relies on the coordination and leadership of the coercive power, and moderate punishment is vital to the promotion and implementation of CLPP. 
TABLE 4: Analysis of the stability of the equilibrium point between the local government and farmers.

\begin{tabular}{|c|c|c|c|c|}
\hline Equilibrium point & $a_{11}$ & $a_{12}$ & $a_{13}$ & $a_{14}$ \\
\hline $\begin{array}{l}A^{*}(0,0) \\
B^{*}(0,1) \\
C^{*}(1,0) \\
D^{*}(1,1) \\
E^{*}\left(q^{*}, \partial^{*}\right)\end{array}$ & $\begin{array}{c}-2 E_{1}-B_{1}+H_{3}+B_{3} \\
-2 E_{1}-B_{1}+H_{3}+B_{3}-J_{1}+N_{1} \\
-\left(-2 E_{1}-B_{1}+H_{3}+B_{3}\right) \\
-\left(-2 E_{1}-B_{1}+H_{3}+B_{3}-J_{1}+N_{1}\right) \\
0\end{array}$ & $\begin{array}{c}0 \\
0 \\
0 \\
0 \\
P_{2}\end{array}$ & $\begin{array}{c}0 \\
0 \\
0 \\
0 \\
Q_{2}\end{array}$ & $\begin{array}{c}M_{1}+2 H_{1}-L_{1}-2 I_{3}+H_{5} \\
-\left(M_{1}+2 H_{1}-L_{1}-2 I_{3}+H_{5}\right) \\
2 I_{3}-M_{1}+L_{1} \\
-\left(2 I_{3}-M_{1}+L_{1}\right) \\
0\end{array}$ \\
\hline Numerical & Symbols & \multicolumn{2}{|c|}{$\operatorname{Tr} J$} & Stability \\
\hline $\begin{array}{l}R * U \\
T *(-U) \\
(-R) * X \\
(-T) *(-X) \\
P_{2} * Q_{2}\end{array}$ & $\begin{array}{l}- \\
+ \\
- \\
+\end{array}$ & $\begin{array}{c}R+U \\
T-U \\
(-R)+X \\
(-T)-X \\
0\end{array}$ & $\begin{array}{l}+ \\
- \\
+ \\
+\end{array}$ & $\begin{array}{l}\text { Unstable point } \\
\text { ESS } \\
\text { Unstable point } \\
\text { Unstable point } \\
\text { Saddle point }\end{array}$ \\
\hline $\begin{array}{l}\text { Note. } \quad \text { Let } \\
P_{2}=q^{*}\left(1-q^{*}\right)\left(4 E_{1}\right.\end{array}$ & $\begin{array}{cc}-B_{1}+H_{3}+B_{3}, & T=-2 E_{1}-B_{1} \\
\text { and } Q_{2}=\partial^{*}\left(1-\partial^{*}\right)\left(4 I_{3}-2 M_{1}+2 I\right.\end{array}$ & $\begin{array}{l}-J_{1}+N_{1} \\
\left.-H_{5}\right)\end{array}$ & $U=M_{1}+2 H$ & $2 I_{3}+H_{5}, \quad X=2 I_{3}-M_{1}+L_{1}$ \\
\hline
\end{tabular}

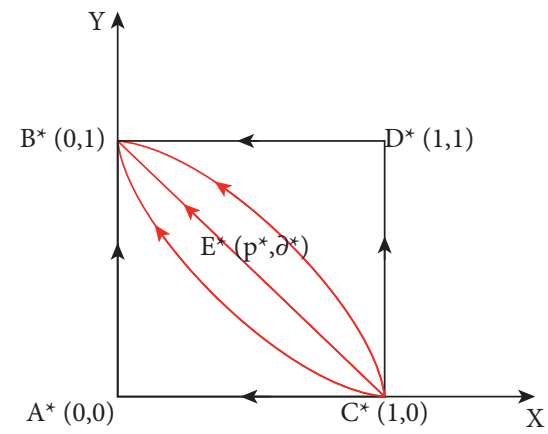

Figure 2: Copying dynamic phase diagram of the local government and farmers.

However, when the local government faces challenging targets and excessive penalties, grassroots cadres will respond through various informal methods and adopt flexible strategies for implementing CLPP.

When the direct cost of strict supervision by the central government $C_{1}$ gradually becomes smaller, the game equilibrium will be broken. Given that $C_{1}$ is small enough, the equilibrium is rebuilt at the new stability point $D(1,1)$, as shown in Figure 3. At this time, the stability strategies of the central government and the local government are strict supervision and faithful implementation, respectively. When the central government adopts a strict supervision strategy, if the penalties for illegal activities on cultivated land are increased, the behavioral strategy of the local government can be changed from flexible implementation to faithful implementation and will shorten the time for the game system to reach the optimal equilibrium state. Therefore, the central government should pay the local government cultivated land protection fees first to ensure that the income of local government from implementing CLPP is not lower than the maximum benefit of using cultivated land for nonagricultural purposes. Furthermore, the central government needs to conduct occasional random checks (including the quantity and quality of cultivated land), reward the local government that has done a good job, and severely penalize those officials who flexibly implement CLPP. Since establishing the national land inspection system, the central government's efforts to control the illegal use of cultivated land have been increasing year by year. However, when local officials conspired to participate in the illegal use of cultivated land, illegal cases of cultivated land became more concealed and challenging to investigate. Therefore, reducing the cost of supervision of the central government and improving the efficiency of supervision has become the key to improving the implementation force of CLPP.

3.2. Impact of Rights-Safeguarding Cost on the State of Evolutionary Equilibrium. This study uses simulation tools to simulate the dynamic evolutionary process from the initial value point to the equilibrium point of both stakeholders and intuitively observe the dynamic evolutionary process of strategic choices of local government and farmers. This study verifies the impact of the cost of rights-safeguarding on the implementation of CLPP by controlling the other parameters unchanged under the ideal model, and $H_{5}$ takes 3, 5, 7, and 9 for simulation experiments. The simulation results are shown in Figure 4. In this case, the equilibrium point of the evolutionary game strategy between the local government and farmers finally converges to $B^{*}(0,1)$, forming a conspiracy behavior that is not conducive to the implementation of CLPP, which is flexible implementation and cooperation, respectively. Therefore, the smaller the cost paid by the local government and farmers for conspiring to conduct 

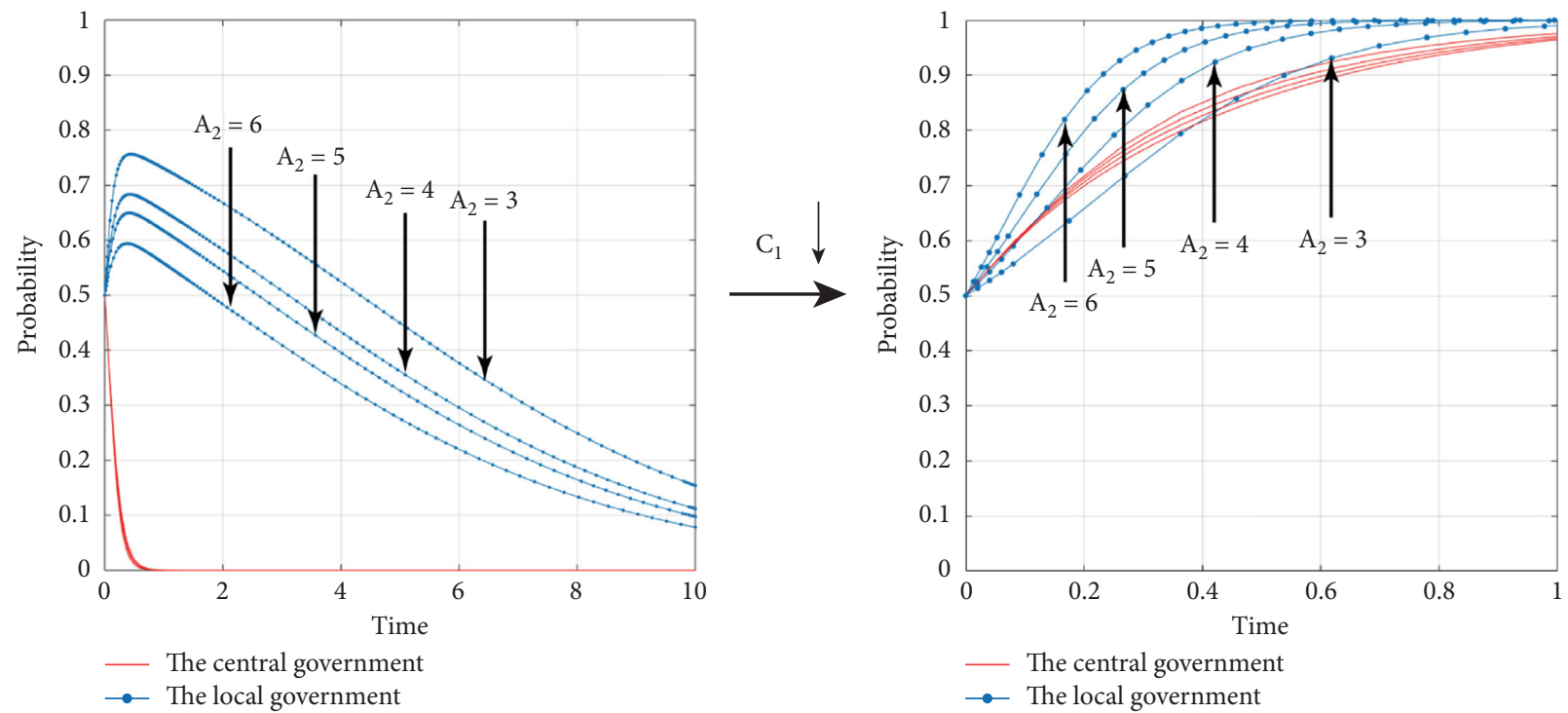

FIGURE 3: Evolution trajectory of the game behavior between the central government and the local government under different punishment intensity.

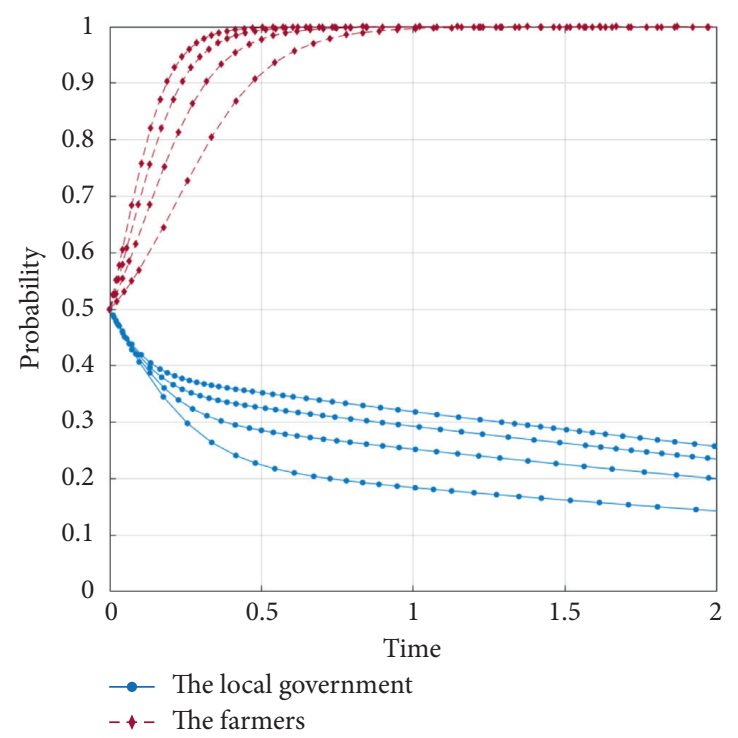

FIGURE 4: Evolution trajectory of the game behavior between the local government and farmers under different rights-safeguarding cost.

cultivated land destruction, illegal land occupation, and illegal reclamation behaviors, the greater the possibility of them implementing CLPP flexibly. Furthermore, with the increase in the cost of protecting farmers' rights, the expected benefits of implementing CLPP have decreased, and the possibility of rights-safeguarding has also decreased. For pure farmers whose main income is from agriculture, the nonagriculturalization of cultivated land can easily lead to a significant reduction in the sustainability of their livelihoods. Moreover, in the current pattern of nonagriculturalization of cultivated land in China, the corruption of government officials and the trading of power and money by developers are extremely harmful to the deprivation of the rights and interests of pure farmers. Therefore, during the game between farmers and stakeholders, such as local governments, village committees, and land developers, once farmers feel the corruption, sense of unfairness, and serious damage to their interests behind the nonagriculturalization of cultivated land, they will have strong willingness to defend their rights. Unfortunately, this only happens when the cost of rights-safeguarding of farmers is relatively low. Given the rent-seeking behavior of cultivated land by the local government and the lack of legal organizations representing rights and interests of farmers, farmers often need to take noninstitutionalized violent actions (behaviors such as sitting still, self-harming, and smashing) to defend their rights, which in turn poses a serious threat to property and lives of farmers. Furthermore, some local governments are 
accustomed to adopting "transactional," "bribery," and "buying-out" methods to increase the nonagricultural income of farmers. Therefore, when the rights-safeguarding channel is not smooth, the rights-safeguarding mechanism is not sound, and the cost of rights-safeguarding is relatively high, farmers are more inclined to assist the local government in implementing CLPP flexibly.

\section{Conclusion and Policy Implications}

4.1. Conclusion. This study analyzes the logic of the implementation of CLPP by the central government, the local government, and farmers and uses the idea of the evolutionary game to construct a game payoff matrix for all stakeholders. On this basis, this study examines the choices of different stakeholders for CLPP implementation behavior driven by different interests and, through simulation analysis, draws the following conclusions:

(1) The various stakeholders in the implementation system of CLPP have their interests, inconsistencies are found in the goals of cultivated land protection, and conflicts of interest often occur, resulting in low efficiency in the implementation of CLPP. The formulation and implementation of CLPP play a decisive role in national food security and social stability. To improve the vitality of policy implementation, coordinating the interests of all stakeholders is necessary.

(2) Adjusting the punishment intensity can realize the stable strategy of "strict supervision, faithful implementation" and "slack supervision, flexible implementation." The change of punishment intensity has little effect on the decision-making willingness of the central government and has a greater impact on the decision-making willingness of the local government. Within a moderate range, the greater the punishment, the stronger the willingness of the local government to implement CLPP faithfully. However, excessive punishment will create incentives for its flexible implementation of CLPP. The supervision cost $C_{1}$ in the game system has a threshold. Only when the supervision cost is set below the threshold, can both stakeholders of the game realize the ideal situation of "strict supervision and faithful execution."

(3) The local government and farmers only have one possible stable equilibrium point, and the long-term equilibrium of the system tends to be a stable state of "flexible implementation and cooperation." The rights protection behavior of farmers is often difficult to achieve under the local government's intervention and promotes the local government's impulse to implement CLPP flexibly. Therefore, farmers' awareness of rights-safeguarding should be improved, and their rights-safeguarding costs should be reduced to provide protection for exposing the illegal use of cultivated land by the local government, thereby breaking the game balance.
4.2. Policy Implications. Based on these conclusions, this study recommends the following policies:

(1) To solve the problem of inconsistent cultivated land protection goals between the central government and local governments in the principal-agent relationship, supervision and incentives are two mechanisms that can be used. Moreover, a complementary relationship exists between the two aspects. Incentive refers to the use of material or spiritual rewards to encourage local governments to protect cultivated land. Supervision means that the central government monitors, supervises, and manages the links, processes, and results of cultivated land protection for local governments; hence, local governments strictly implement CLPP. In particular, the Chinese government should establish CLPP based on the level of food security and seek a reasonable boundary between government control and market operations. The central government should designate pollution-free, green, and organic cultivated land as permanent basic farmland protection zone and strictly control the intensity of supervision. After permanent basic farmland is delineated, incentive measures and dynamic supervision are needed to improve productivity. After ensuring absolute food security, food has the attributes of a quasipublic product, and the market can be appropriately used to improve the efficiency of land resource allocation. Local governments can use the national unified market to transfer cultivated land management rights. The government should also ensure the quality and ecological balance of occupied and supplemented cultivated land.

(2) The accurate implementation of CLPP requires substantial investment in supervision funds and also administrative, social, and legal supervision systems from the central government to local governments. Therefore, the central government must continue to strictly punish the illegal use of cultivated land and accelerate the improvement of the land inspection system. The establishment and improvement of a land inspection system in China aims to provide various forms of inspection services through land inspection agencies to strengthen the cultivated land protection and management for local governments. On the one hand, this system can regulate the cultivated land protection behavior of local governments. On the other hand, by promoting the local government to implement the macro policy of land intensive use, it is also conducive to reducing the occupation of cultivated land by construction land, thereby increasing the extent of cultivated land. Meanwhile, cultivated land occupation tax is imposed by the Chinese government on the occupation of cultivated land to protect the existing cultivated land. Given the scarcity of cultivated land resources in China, the quality level and ecological security of cultivated land are key factors that determine food security. The use of cultivated land quality and ecology as bases for tax calculation can effectively avoid the problem of 
equal taxation of cultivated land of different quality levels or different ecological status (in the case of other conditions being equal). In addition, taxation must consider the issue of fairness. Different regions have different levels of economic development, and the corresponding tax amounts should also be different. Economic development level is an important factor in the formulation of tax rates. On the one hand, it can reflect the affordability of a certain area for taxation. On the other hand, it is also one of the bases for the role of tax. Therefore, the quantity, quality, ecology of cultivated land, and local economic development of the region should be regarded eventually as the constituent elements of cultivated land occupation tax.

(3) The Chinese government should accelerate the establishment of a rights protection mechanism to ensure that farmers express their demands in the fastest way. The establishment of a legal and smooth rights protection mechanism can resolve class conflicts in the embryonic stage and prevent the occurrence of excessive behavior. First, farmers' awareness of legal rights protection should be cultivated, and their legitimate rights and interests must be protected through legal means. Second, the organization of farmers and negotiating ability of disadvantaged groups should be improved. In addition, local governments must use the rule of law thinking to build a platform for the protection of farmers' rights to ensure that they have laws to follow and express smoothly when their legal rights are violated. Moreover, the wishes of farmers should be fully respected and the implementation method of CLPP must be rationally adjusted. Given the improvement of subsidies and support policies, subsidy methods should be continuously enriched to effectively improve the efficiency of agricultural subsidies and income of farmers (e.g., cash, in-kind, and social security compensations). The determination of scientific subsidy standards for cultivated land protection can help farmers increase their agricultural income through multiple channels. Additional publicity and popularization of CLPP are also needed in the implementation process.

\section{Data Availability}

The data used to support the findings of this study are available from the corresponding author upon request.

\section{Conflicts of Interest}

The authors declare that they have no conflicts of interest regarding the publication of this paper.

\section{Authors' Contributions}

Xinhai Lu and Yanwei Zhang contributed equally to this work and share the first authorship.

\section{Acknowledgments}

The authors would like to thank Jingwen Liao for her contribution to the photo editing in the article. This research was supported by the National Natural Science Foundation of China (no. 71673096); the National 985 Project of Nontraditional Security at Huazhong University of Science and Technology, China; and the Fundamental Research Funds for the Central Universities, HUST (no. 2021WKZDJC001).

\section{References}

[1] M. Kuiper and H. Cui, "Using food loss reduction to reach food security and environmental objectives-A search for promising leverage points," Food Policy, vol. 98, Article ID 101915, 2020.

[2] X. Liu, Y. Xu, B. A. Engel et al., "The impact of urbanization and aging on food security in developing countries: the view from Northwest China," Journal of Cleaner Production, vol. 292, Article ID 126067, 2021.

[3] T. Reardon, L. Lu, and D. Zilberman, "Links among innovation, food system transformation, and technology adoption, with implications for food policy: overview of a special issue," Food Policy, vol. 83, pp. 285-288, 2019.

[4] M. Kassie, M. Fisher, G. Muricho, and G. Diiro, "Women's empowerment boosts the gains in dietary diversity from agricultural technology adoption in rural Kenya," Food Policy, vol. 95, Article ID 101957, 2020.

[5] P. Schneider and F. Asch, "Rice production and food security in Asian Mega deltas-A review on characteristics, vulnerabilities and agricultural adaptation options to cope with climate change," Journal of Agronomy and Crop Science, vol. 206, no. 4, pp. 491-503, 2020.

[6] J. Fan, L. Wang, J. Qin, F. Zhang, and Y. Xu, "Evaluating cultivated land stability during the growing season based on precipitation in the Horqin Sandy Land, China," Journal of Environmental Management, vol. 276, Article ID 111269, 2020.

[7] S. Guo, Y. Wang, Y. Wang, M. Wang, P. He, and L. Feng, "Inequality and collaboration in north China urban agglomeration: evidence from embodied cultivated land in JingJin-Ji's interregional trade," Journal of Environmental Management, vol. 275, Article ID 111050, 2020.

[8] X. Lu, Y. Zhang, and H. Tang, "Modeling and simulation of dissemination of cultivated land protection policies in China," Land, vol. 10, no. 2, p. 160, 2021.

[9] G. Xu, X. Huang, T. Zhong, Y. Chen, C. Wu, and Y. Jin, "Assessment on the effect of city arable land protection under the implementation of China's National General Land Use Plan (2006-2020)," Habitat International, vol. 49, pp. 466473, 2015.

[10] Y. Wu, L. Shan, Z. Guo, and Y. Peng, "Cultivated land protection policies in China facing 2030: dynamic balance system versus basic farmland zoning," Habitat International, vol. 69, pp. 126-138, 2017.

[11] X. Zhang and X. Lyu, "Reform logic of territorial space use regulation and the response path of land spatial planning," Journal of Natural Resources, vol. 35, pp. 1261-1272, 2020.

[12] K. Shi, Q. Yang, Y. Li, and X. Sun, "Mapping and evaluating cultivated land fallow in Southwest China using multisource data," The Science of the Total Environment, vol. 654, pp. 987-999, 2019. 
[13] H. Wang, C. He, W. Li, X. Nie, H. Zhong, and L. Wen, "Will transferable development rights (TDR) increase regional economic imbalance?-A quota transaction case of cultivated land conversion and reclamation in Guangxi, China," Habitat International, vol. 104, Article ID 102254, 2020.

[14] S. Guo and Y. Shi, "Infrastructure investment in China: a model of local government choice under land financing," Journal of Asian Economics, vol. 56, pp. 24-35, 2018.

[15] H. Liu and Y. Zhou, "Farmers' cognition and behavioral response towards cultivated land quality protection in northeast China," Sustainability, vol. 10, p. 1905, 2018.

[16] G. Li, C. Fang, D. Qiu, and L. Wang, "Impact of farmer households' livelihood assets on their options of economic compensation patterns for cultivated land protection," Journal of Geographical Sciences, vol. 24, no. 2, pp. 331-348, 2014.

[17] D. Xiao, H. Niu, L. Fan, S. Zhao, and H. Yan, "Farmers' satisfaction and its influencing factors in the policy of economic compensation for cultivated land protection: a case study in chengdu, China," Sustainability, vol. 115787 pages, 2019.

[18] S. Zhang, W. Hu, J. Zhang, M. Li, and Q. Zhu, "Mismatches in suppliers' and demanders' cognition, willingness and behavior with respect to ecological protection of cultivated land: evidence from caidian district, wuhan, China," International Journal of Environmental Research and Public Health, vol. 17, no. 1156, 2020.

[19] X. Zhou, X. Li, and D. Chai, "The inter-regional farmland protection compensation distribution index system and application-A case study in fuzhou city," Economic Geography, vol. 36, pp. 152-158, 2016.

[20] Y. Shi, C. Li, and M. Zhao, "The impact of non-market value cognition and social capital on farmers'willingness in farmland protection cooperation," China population, resources and environment, vol. 29, pp. 94-103, 2019.

[21] B. Yang, Z. Wang, L. Zou, and H. Zhang, "Exploring the ecoefficiency of cultivated land utilization and its influencing factors in China's Yangtze River Economic Belt, 2001-2018," Journal of Environmental Management, vol. 294, Article ID 112939, 2021.

[22] J. H. Lee, R. Yamaguchi, H. Yokomizo, and M. Nakamaru, "Preservation of the value of rice paddy fields: investigating how to prevent farmers from abandoning the fields by means of evolutionary game theory," Journal of Theoretical Biology, vol. 495, Article ID 110247, 2020.

[23] X. Zhang, H. Bao, and M. Skitmore, "The land hoarding and land inspector dilemma in China: an evolutionary game theoretic perspective," Habitat International, vol. 46, pp. 87-195, 2015.

[24] Y. Chen, D. Zhu, and L. Zhou, "A game theory analysis of promoting the spongy city construction at the building and community scale," Habitat International, vol. 86, pp. 91-100, 2019.

[25] H. Zanjanian, H. Abdolabadi, M. H. Niksokhan, and A. Sarang, "Influential third party on water right conflict: a Game Theory approach to achieve the desired equilibrium (case study: ilam dam, Iran)," Journal of Environmental Management, vol. 214, pp. 283-294, 2018.

[26] Y. Wang, D. Wang, and X. Shi, "Exploring the dilemma of overcapacity governance in China's coal industry: a tripartite evolutionary game model," Resources Policy, vol. 71, Article ID 102000, 2021.

[27] X. Gao, J. Shen, W. He et al., "An evolutionary game analysis of governments' decision-making behaviors and factors influencing watershed ecological compensation in China," Journal of Environmental Management, vol. 251, Article ID 109592, 2019.

[28] H. Xie, W. Wang, and X. Zhang, "Evolutionary game and simulation of management strategies of fallow cultivated land: a case study in Hunan province, China," Land Use Policy, vol. 71, pp. 86-97, 2018.

[29] L. Song, P. Lyu, and Y. Cao, "Multi-party game and simulation in the withdrawal of rural homestead: evidence from China," China Agricultural Economic Review, vol. 13, no. 3, pp. 614638, 2021.

[30] K. Hong, Y. Zou, M. Zhu, and Y. Zhang, "A game analysis of farmland expropriation conflict in China under multi-dimensional preference: cooperation or resistance?" Land, vol. 10124 pages, 2021.

[31] J. Shen, X. Gao, W. He et al., "Prospect theory in an evolutionary game: construction of watershed ecological compensation system in Taihu Lake Basin," Journal of Cleaner Production, vol. 291, Article ID 125929, 2021.

[32] Y. Xue, W. Luan, Y. Yang, and H. Wang, "Evolutionary game for the stakeholders in livestock pollution control based on circular economy," Journal of Cleaner Production, vol. 282, Article ID 125403, 2021.

[33] Z. Wang, M. Li, D. Wang, and Q. Chen, "Evolution of extortion in the social-influenced prisoner's dilemma," Modern Physics Letters B, vol. 30, Article ID 1650029, 2016. 